\title{
Women Suicide Attempted By Burning in Sulaimania city
}

Accepted: 14/5/ 2011

\section{Ari Raheem Qadir*}

\section{Abstract}

Background and objectives: This study way conducted in order to investigate the magnitude of the women suicide attempted by burning in Sulaimani and to ascertain the factors related to female suicide, including sociocultural factors and ways to solve this problem.

Methods: The present study is a prospective study of self inflicted burns by women treated at the burn unit of Sulaimani teaching hospital and Emergency hospital over five years period from 1st January 2003 to 31st December 2007.

Results: Out of the total number of 760 admissions to burn unit over the period, 386 $(50.2 \%)$ patients were positively identified as having attempted suicide by burning. Of them $345(46.6 \%)$ patients were females and 41 were males. The Suicide attempted was more common in the marriages women $258(74.7 \%)$ and women with low educational level168 (48.7\%). The most common causes of suicide were arrogant husband (60) $(17.4 \%)$ and forced marriage (58) (16.8\%).

Conclusion: Burning by kerosene is a common, traditional, and dramatic way of attempting suicide by women in Sulaimani. We suggest that Kurdish women organizations or other related authorities have to start programs for communications with women to rescue those in desperate situations, and suicide prevention programs in Kurdistan to prevent suicide as well as to evaluate prevention programs to identify evidence-based practices that are culturally appropriate and affordable within severe resource constrains.

Key word:

\section{Introduction}

Suicide is the deliberate act of self-destruction; it is ultimately an individual action but results from a combination of psychological processes, social circumstances and cultural influences. ${ }^{1}$ Suicide attempt by burning is an especially violent and bizarre means of self destruction. ${ }^{2}$ Self-inflicted burn injuries account for about $4 \%$ of burns admission world wide. ${ }^{3}$ However, there is great variation $0.37 \%{ }^{(4)}$ to $14 \%{ }^{5}$ with deliberate self-burning being more common in certain cultural, racial and religious groups. The most common reasons for deliberate self burning have been categorized by Erzurum and Varcellotti as being escape from stress sadness
$54.5 \%$, and hallucinations/delusions 18.1\%. ${ }^{6}$ Studies conducted in Iran showed that the majority of women suicide who attempted by burning is committed in 15-24 years age group and with increase of age group the rate of suicide decline. ${ }^{7}$ Our study was conducted in order to investigate the magnitude of this problem in Kurdistan and to ascertain the factors related to female suicide, including sociocultural factors and ways to solve this problem.

\section{Methods}

The present study is a prospective study of self inflicted burns by women treated at the burn unit of Sulaimani teaching hospital and Emergency hospital over five years period from 1st January 2003 to 31st

* Department of Surgery, College of Medicine, Sulaimanya University, Sulaimanya, I raq. 
December 2007. Sulaimani is one of the big cities in the Kurdistan of the Iraq; population size is about 1.5 million. The registration of the patients included information on age, sex, marital status, methods used for suicide, place of suicide, psychiatric history, family relations, social state, cause and circumstances leading to the self-inflicted burn, educational state, information on the burn wound, the date and time of burn, treatment, length of hospital stay, total body surface area (TBSA) burned and the out come.

\section{Results}

Out of the total number of 760 admissions to burn unit over the mentioned period (519 female and 241 male), 386(50.7\%) patients were positively identified as having attempted suicide by burning. Of these, 345 (46.6\%) patients were females and 41 (4.1\%) were males (Figure1).

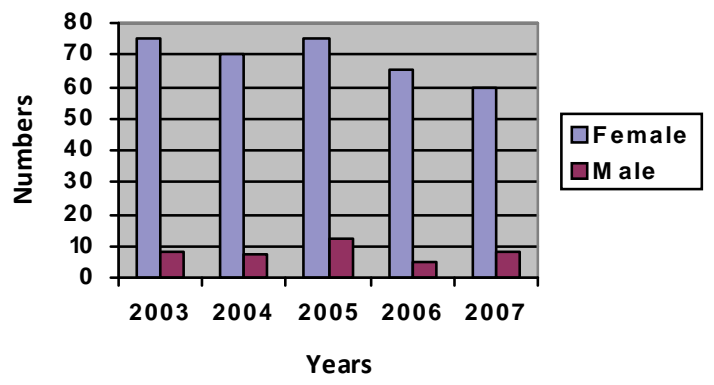

Figure 1: Numbers and sex distribution of suicidal burn.

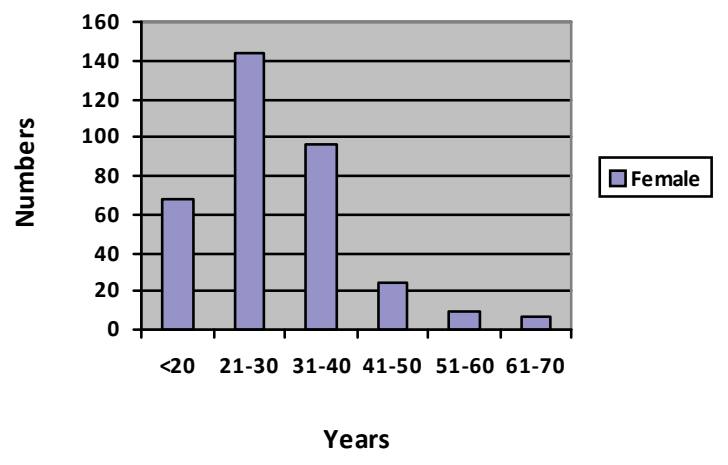

Figure 2: Numbers and age distribution of female attempt suicide
The method used by suicidal patients in this series was mostly to pour kerosene over themselves and to set light to it. the suicide attempts occurred at home. The Suicide attempted was more common in the married women 258(74.7\%) (Figure3) and women with low educational level168 (48.7\%) (Figure 4).

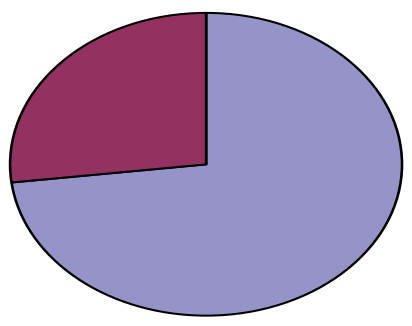

$\square$ Married
$\square$ Non-married

Figure 3: Numbers of married and non-married women attempted suicide.

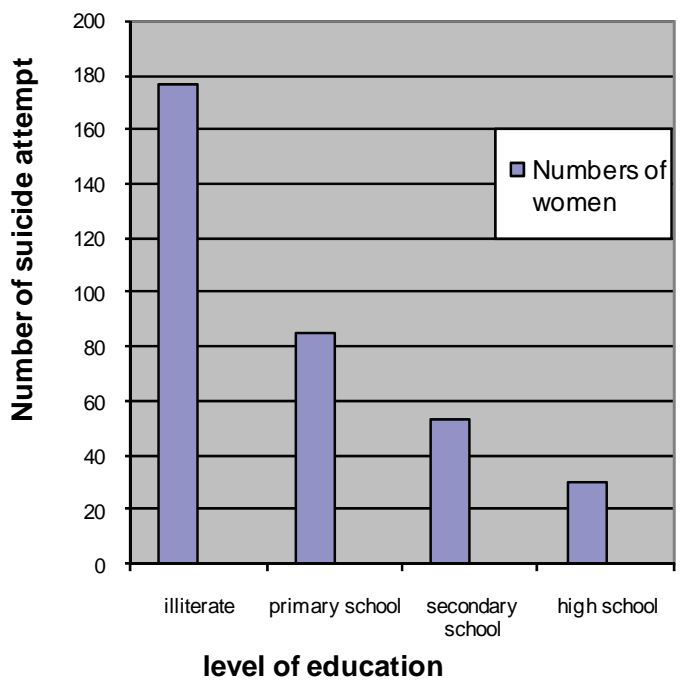

Figure 4: Level of the education among women attempt suicide 
The most common causes of suicide were arrogant husband (60) (17.4\%) and forced marriage (58) (16.8\%). The psychiatric histories of all the patients were reviewed. Fifty-four patients $(15.6 \%)$ were found to have a previous psychiatric disorder; of those, thirty patients had documented depression and 14 patients were known to have schizophrenia (Figure 5).

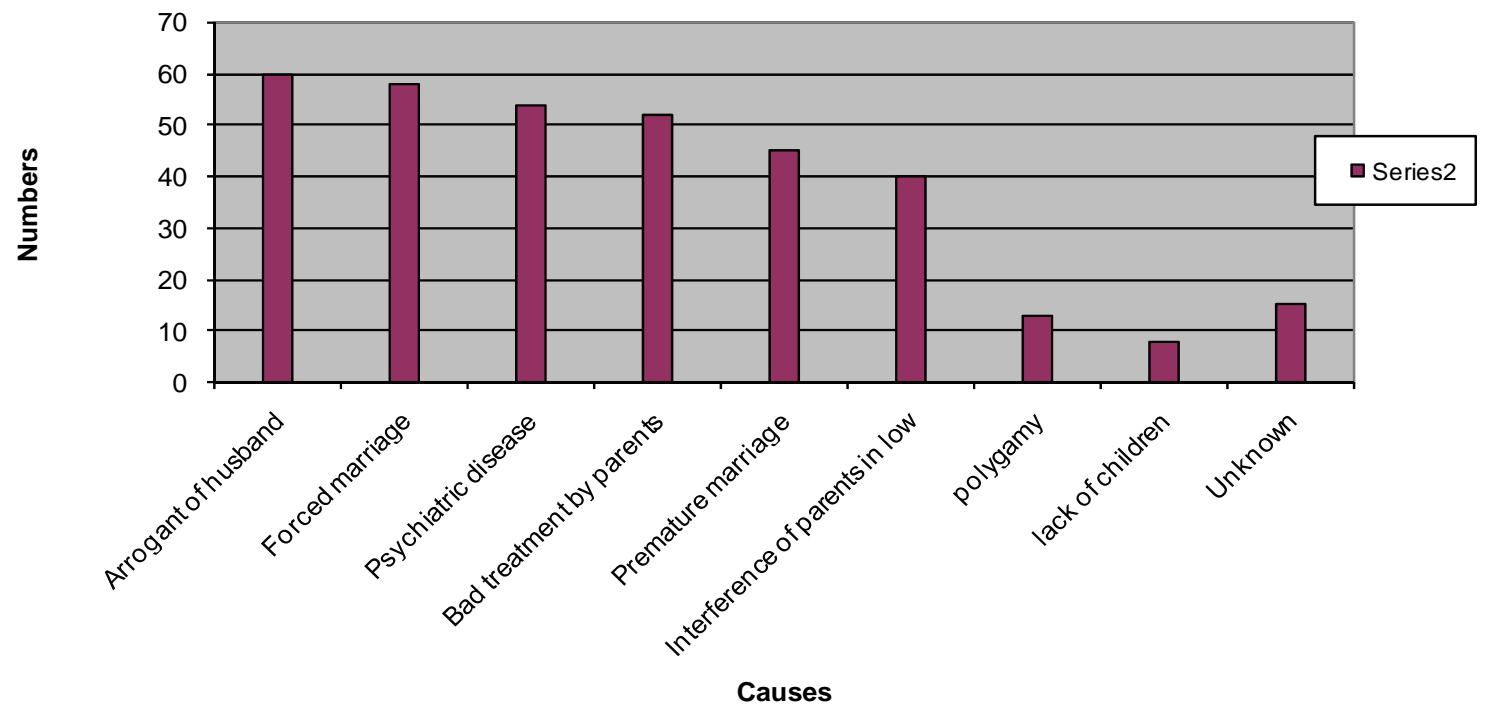

Figure 5: Common causes of suicidal attempts

Suicidal burns tend to be major injuries with high TBSA burn. The TBSA burned in the suicidal burns in this series varied from 25 to $98 \%$ ( average, 55\%). Most patients suffered deep second and third degree burns.
Following the hospitalization, all of the patients were treated but, unfortunately, (166) died (48.1\%) in spite of our close monitoring and follow-up (Table1).

\begin{tabular}{ccccc} 
Percentage of burn & Numbers of female patients & Percentage & Mortality & Percentage \\
\hline Less than 20 & 26 & 7.6 & - & - \\
$21-40$ & 62 & 17.9 & 6 & 1.7 \\
$41-60$ & 135 & 39.1 & 38 & 11 \\
$61-80$ & 68 & 19.7 & 68 & 19.7 \\
More than80 & 54 & 15.7 & 54 & 15.6 \\
TOtal & 345 & 100 & 166 & 48.1
\end{tabular}

Table 1: Percentage of burn and mortality rate. 


\section{Discussion}

Suicide by self-burning is the most dramatic form of self-harm. Self-burning has been reported rarely (1\%) both in the UK ${ }^{8}$ and in the USA. ${ }^{9-11}$ However, it is relatively common $(77 \%)$ as a method of suicide in Israel. ${ }^{12}$ In our series, it occurred as (50.2\%) of admissions at our center over a 5 years period and the self-inflicted method was almost always a flame burn injury. The findings in our study suggest that:

1. There have been significant increases in reported suicides among women during this period.

2. Most of women are young.

3. The following reasons were found to be the motives behind their drift toward inflicting upon themselves the final solution:

- Marriage problems which may include forced marriage, premature marriage, age difference, polygamy.

- House hold problems like dominating behavior of the husband, interference of parents in low, restriction of liberty of movements of the wife, financial problems.

- Behavioral problems and tendency towards modernism by women.

- Lack of normal familial atmosphere such as love and parental sentiments due either to the absence of one of the parents or both.

- Women have no rights to decide separation (divorce) which is sometimes the only solution to get rid of miserable marital life.

4. Because suicide is specifically proscribed by Islamic law, this is the factor in "masking" suicide as accidental to reduce the potential for social stigma.

5. Suicidal burns were found to have a high TBSA and a high mortality rate.

6. As a traditional method of women suicide it can be considered as a tradition in Kurdish society.

\section{Conclusion}

Burning by kerosene is a common, traditional, and dramatic way of attempting suicide by women in Kurdistan. We suggest that Kurdish women organizations or the regional government should:

1- Start programs for communications with women so that to rescue those in desperate situations,

2 - Hold conferences in local villages to educate teachers and other community leaders about the problem.

3- Start suicide prevention programs in Kurdistan to prevent suicide as well as to evaluate prevention programs to identify evidence-based practices that are culturally appropriate and affordable within severe resource constrains.

4- Build counseling centers to teach men and women the basics of relationships

5- Help those who tried to kill themselves through hospitals need post-discharge centers in the hospitals with psychologists and counselors to train victims how to cope with their new lives, to make them feel acceptable again and, if their families have deserted them, to help them get jobs.

\section{References}

1.Louis Appeby: Suicide and self harm. In:Robin murray, Peter Hill and PeterMcGuffin. The essentialsof postgraduate psychiatry, $3^{\text {rd }}$ edition. Cambridge University press, 1997;551-562.

2.Palmu R,Isometsa E, Suominen $K$ et al. Selfinflicted burns: an eight year retrospective study in Finland. Burns 2004;30:443-7.

3. Horner B M,Ahmadi $\mathrm{H}$, Mulholland $\mathrm{R}$ et al. Case controlled study of patients with self-inflicted burns. Burns 31(2005):471-5.

4. Meir PB, Sagi A Ben $Y Y$ et al. Suicide attempts by self-immolation-our experience. Burns 1990;16:257-8.

5.Klasen HK, von der Tempel, Hekert $\mathrm{J}$ et al. Attempt suicide by means of burns. Burns 1989;15:88-92.

6. ErzurumV, Varclloti MD. Self-inflicted burn injuries. J Burn Care Rehabile 1990;20-22-4.

7.Askari S. Women, main victims of suicide in Iran. Culture of development 1998;3:37-42.

8.Ashton JR, Dorman S, Suicide by burning as an epidemic phenomina: an analysis of 82 death and 
inquests in England and Wales in 1978-9.Psycho. Med., 11:735, 1981.

9.Andreasen N.C, Noyes R, Suicide attempt by selfimmolation. AM. J.Psychiatry, 132:554,1975.

10.Kukunishi et al. Burns in a suicide attempt related to psychiatric side effects of interferon. Burns ,1998 Sep;24(6):581-3 .

11.Stepakoff S. 1998. Effects of sexual victimization on suicidalideation and behavior in U.S. college women. Suicide Life Threat Behav 28:107-126.

12.Modan B, Nissenkom I, Lewkowski S R. Comparative epidemiologicalaspect of suicide and attempted suicide in Israel. AM. J, Epidemiology, $91: 383,1970$ 